\title{
ГЕНЕЗИС ВЗГЛЯДОВ НА КАТЕГОРИЮ ЭФФЕКТИВНОСТЬ БИЗНЕСА И ОСОБЕННОСТИ ЕЁ ОЦЕНКИ
}

\author{
(c) 2021 Гавель Ольга Юрьевна \\ $\mathrm{PhD}$, доцент департамента бизнес-аналитики \\ Финансовый университет при Правительстве Российской Федерации, Россия, Москва \\ E-mail: oygavel@fa.ru
}

В статье исследован феномен категории «эффективности производства» и её виды на основе систематизации и обобщения взглядов зарубежных и отечественных ученых на проблему определения эффективности бизнеса. При этом были изучены точки зрения ведущих научных школ, позволяющих выявить основные тенденции, влияющие на порядок определения и оценки эффективности деятельности организаций на современном этапе развития общества.

Ключевые слова: теория эффективности, виды эффективности, оценка эффективности бизнеса, управление.

Приоритет введения категории эффективность в экономическую науку принадлежит английскому ученому Д.Риккардо. Согласно теории «сравнительных преимуществ» каждый экономический агент должен специализироваться на производстве товаров лучшего качества с «относительно более низкими издержками рабочего времени по сравнению с другими странами», что обеспечивает каждому из них доступ к большему количеству товаров потребления, чем в условиях отсутствии специализации и торговли [1]. В дальнейшем его взгляды были развиты в работах американского экономиста Г.Хаберлера, который ввел понятие альтернативных издержек.

К. Маркс и Ф.Энгельс заложили основу теории экономической эффективности, введя в научный оборот категорию «прибавочная стоимость» [2]. Экономическая эффективность процесса труда рассматривалась Марксом как отношение его результата к совокупным затратам с учетом особых функций средств и предметов труда и результативности их использования. Таким образом, он впервые обратился к исследованию проблемы эффективности процесса труда в целом, а также к вопросу о частной эффективности использования средств и предметов труда, т.е. технической и экономической эффективности. Им была определена экономическая эффективность общественного способа производства через призму эффективности использования капитала. Эффективность промышленного капитала характеризовалась соотношением предпринимательского дохода, представляющего собой разность между валовой прибылью и процентами по кредиту, и суммы авансированного капитала или издержек производства, а товарно-торгового и денежно-торгового капитала как соотношения торговой прибыли к авансированному торговому капиталу или к сумме чистых и дополнительных издержек обращения.

Значительный вклад в развитие теории экономической эффективности внес австрийский экономист Й.Шумпетер. По его мнению, для обеспечения устойчивого прогресса экономики важен не столько экономический рост, сколько позитивные изменения и инновации, т.е. нечто, приводящее к замене старого на новое в процессе «свободного творчества». В работе «Теория экономического развития» в основу концепции эффективного развития им были положены две фундаментальные основы: эффективное использование ресурсов и экономическое равновесие [3]. Современное развитее экономики неуклонно подтверждает мнение ученого относительно роли перманентных изменений технического, технологического и организационного типа, которые периодически принимают революционные формы.

Шумпетер считал инновации (нововведения) основой конкуренции нового типа, «эффективной конкуренции», гораздо более действенной, чем ценовая, которые открывают возможности не только изменения продукции и совершенствования технологий, но и непосредственно оказывают влияние на изменения структуры спроса, условий ценообразования и формирование издержек. Им была установлена 
связь между производственной и экономической эффективностью, инновациями и жизнеспособностью предприятия.

Й.Шумпетер ввел также понятие «эффективной монополии», отличное от традиционных монополий, основанных на особых правах и привилегиях, собственности на ограниченные ресурсы или дефицитные блага. Монопольная прибыль, формируемая вследствие «эффективной монополии», является мощным стимулом к нововведениям, так как время её получения ограничено временем диффузии инновации в бизнес-среду, в результате чего она становится действенным инструментом развития и прогресса капиталистической экономики. Она всегда находится под угрозой, испытывая давление от «конкуренции со стороны нового товара, новой технологии, нового источника снабжения, нового типа организации...», что вынуждает успешные организации бороться за свои лидерские позиции [3].

Перевод экономики на инновационный путь развития представляет предпринимательским структурам одновременно несколько существенных преимуществ:

- экспорт инновационной продукции обеспечивает значительные поступления для развития экономики страны в целом;

- распространение инновационных технологий и оборудования позволяет существенно повысить рыночную конкурентоспособность товаров и организаций их производящих;

- ориентация на создание нематериальных ценностей с последующим их использованием в инновационных продуктах и технологиях создает важные предпосылки для формирования человеческого капитала и повышения уровня образованности и качества жизни;

- применение новых технологий способствует сохранению природных богатств, устранению или, по крайней мере, снижению вероятности экологических и техногенных катастроф.

Инновационная парадигма развития экономики формирует условия для повышения технической, производственно-технологической, социально-экономической и экологической эффективности предпринимательской деятельности, обеспечивая успешным организациям формирование монопольной прибыли на вложенный капитал в период эксклюзивного пользования правами на инновации.

Дальнейший вклад в развитие теории эффек- тивности внес английский экономист Дж. Кейнс. Он подверг критике либеральные экономические теории монетаризма, обосновав необходимость активного участия государства в «дирижизме» деятельности экономических субъектов, обеспечивающем рост их эффективности за счет сокращения неэффективного использования ресурсов и сглаживания последствий кризисных явлений в экономике [4]. Влияние государственных институтов на экономическую эффективность хозяйственной деятельности рыночных субъектов базируется на проводимой фискальной и кредитно-денежной политике, которые становятся стимулами к изменению модели поведения экономических агентов. Исследуя категорию эффективности, Дж. Кейнс ввел понятие «эффективного спроса», который стимулирует предложение и подталкивает развитие производства. Тем самым, понятие спроса соотносилось с понятием объемов производства или предложением, выраженным в денежной форме.

Во второй половине XX века теория эффективности частного и общественного производства получила мощный импульс в развитии. Появилось большое число научных исследований посвященных проблемам комплексной оценки эффективности капиталистического и социалистического производства. В значительной мере под воздействием угроз, связанных с деградацией окружающей среды и исчерпания не возобновляемых ресурсов, в зарубежной литературе все большее внимание отводилась вопросам экологической и социальной ответственности бизнеса как критериев оценки эффективности, а также проблемам формирования и использования человеческого капитала. Таким образом, выделяются экономические, социальные, экологические и технологические аспекты эффективности.

Более детально рассматриваются в исследованиях вопросы взаимосвязи категории «эффективность» с отношениями общественной (государственной) и частной собственностью; разрабатываются проблемы функционирования и симбиоза различных отраслей экономики в рамках вертикально- и горизонтально- интегрированных холдинговых структур; осуществляется исследовательская деятельность в направлении выявления факторов эффективного экономического роста бизнеса. Проявляется интерес, связанный с изучением специфики информационного обеспечения управления и оценки эффективности применительно к отрас- 
левым и клиентским сегментам бизнеса.

В исследованиях отечественных экономистов получило признание, что «количественное выражение определенным способом отношения между эффектом и ресурсами является лишь внешним выражением эффективности. За ним скрывается определенное общественное содержание, сущность эффективности, которую необходимо выявить и изучить» [5]. Эффективность общественного (социалистического) производства определяется соотношением степени достижения общественной цели и объемов используемых ресурсов. При этом не совсем понятным являлся алгоритм формирования этих целей: построение социального государства, оценка динамик воспроизводства капитала или механизм диагностики эффективности используемых ресурсов.

Как в Советской России, так и за рубежом при оценке эффективности широко используются сложные математические модели. В СССР на основе идей МарксаЛ.В.Канторовичем, В.С.Немчиновым, В.В.Новожиловым и Н.П.Федоренко была разработана система моделей планово-административного управления народнохозяйственным комплексом страны $[6,7,8,9]$. Макроэкономические модели, реализующие методический подход, получивший признание как система оптимального планирования экономики, в текущих условиях (отсутствие единства целей бизнеса, власти, наемных работников; неоднородность мотивов ведения бизнеса; недостатки национальной доктрины развития экономики) не могут рассматриваться эффективными инструментами макроэкономического регулирования. Однако они не утратили свою актуальность на микроуровне организации ведения хозяйственной деятельности. Как показывает зарубежный опыт макроэкономического регулирования экономики для достижения оптимальных пропорций между спросом и предложением, при котором обеспечивается максимальная эффективность для всех участников бизнеса, роль макроэкономического моделирования весьма существенна.

Среди зарубежных авторов, внесших значительный вклад в развитии теории эффективного управления бизнесом, необходимо выделить М. Алле, Э.Деминга, П.Ф.Друкера, Г. Минцберга и М. Портера.

«Теорема эквивалентности» французский экономист М.Алле стала краеугольным кам- нем концепции конкурентного планирования применительно к крупным государственным монополиям. Он приводит доказательные подтверждения, что всякая равновесная ситуация рыночной экономики является ситуацией максимальной эффективности и, что всякая ситуация максимальной эффективности является результатом равновесной ситуации в рыночной экономике [10]. Нельзя не согласиться с его точкой зрения на эффективность производства как важнейшее условие достижения рационального использования ограниченных ресурсов и сформулированными принципами достижения максимальной эффективности в экономике:

- децентрализация управление экономикой;

- необходимость реального желания и активности экономических агентов «реализовать возможности, которые открывает и делает технически доступными децентрализация экономики» [10].

По мнению М.Алле, развитие социалистической экономики постоянно тормозилось возникновением «узких мест», которые блокировали весь хозяйственный механизм, тогда как избыточные капиталовложения и наличие избыточных мощностей в капиталистической экономике являлись условием быстрого роста и эволюции экономических структур.

Значителен вклад в теорию управления эффективностью бизнеса американского экономиста П. Друкера, придавшего менеджменту статус научной дисциплины. Им были определены основные критерии, которым должно соответствовать управленческое решение, обоснована методика управления по целям (Management by Object, MBO). П.Друкер отделил понятие результативности (effectiveness), под которым подразумевал «делать правильные вещи» от понятия эффективность (efficiency) - «делать вещи правильно». Причем решению обеих задач он предавал одинаковую важность для жизнеспособности и стратегической конкурентоспособности бизнеса [11].

Американский экономист Эдв. Деминг, разрабатывая теорию эффективного управления фирмой, основанную на мониторинге, поставил под сомнение возможность использования методологии управления по целям (MBO) в условиях состояния неустойчивости внешней среды [12]. Согласно его мнению, длительная неизменность целей и управление, основанное на анализе отклонений, не позволяет лицам, при- 
нимающим решения (ЛПР), своевременно производить корректировку целей. Управление на основе бюджета и анализа отклонений может быть применимо лишь при стабильном состоянии внешней среды и использовании модели бизнес-администрирования в управлении. Эту модель он рассматривал как одну из причин возникновения внутренних деструктивных конфликтов собственников бизнеса, менеджеров и персонала. Современная практика управления подтвердила мнение Эдв. Деминга: в условиях повышенной турбулентности самым важным становится не управление на основе исторических отчетов, а инициация действий активных работников компании по наблюдению за состоянием и перспективами развития операций, процессов, стратегических бизнес-единиц, компании в целом, формирование и эффективное использование человеческого капитала.

Представитель «школы обучения» в менеджменте Г. Минцберг подчеркивал, что стратегия со временем приходит в противоречие с необходимостью приспосабливаться к изменяющейся действительности. Начав с перспективы, ЛПР приходит к необходимости разработки определенной позиции, заключающейся в тщательном формировании программы с соответствующими планами и стратегией, которые сформулированы в виде конкретных моделей решений и действий на отрезке времени [25]. Эффективность бизнеса достигается не только, и не столько за счет правильного целеположения, сколько на основе разработки и реализации конкурентных бизнес-моделей, которые имеют элементы уникальной идентичности и обеспечивают конкурентное преимущество по сравнению с другими организациями.

Модератор теории конкурентной стратегии М.Портер провел разграничение понятий операционной и стратегической эффективности бизнеса [13]. Под операционной эффективностью им понималось выполнение аналогичных операций лучше остальных рыночных игроков: с меньшими издержками, более эффективным использованием имеющихся факторов производства. Однако, чем больше компании занимаются бенчмаркингом, чем больше операций передается на аутсорсинг более эффективным организациям, но нередко одним и тем же, тем более универсальны их виды деятельности, тем более похожими друг на друга они становятся. Таким образом, конкуренция, основывающаяся исключительно на операционной эффективности, носит взаимно деструктивный характер и подрывает силы компаний.

Стратегическое позиционирование означает осуществление отличных от конкурентов видов деятельности или выполнение иными способами схожей деятельности, что, как правило, обеспечивает более высокую ценность для потребителя и/или создает сопоставимую с конкурентами ценность, но характеризующуюся меньшими издержками. «Арифметика максимальной прибыльности» М.Портера заключается в наличии большей ценности, позволяющей компании продавать продукцию по более высоким ценам и достижении более высокой производительности, что обеспечивает снижение издержек [13]. Однако в качестве главной цели управления он видел прибыль, рост которой предполагает не только повышение ценности для потребителя, но и снижение затрат, часть из которых, включая «зарплатные статьи», по сути представляет интересы отдельных групп стейкхолдеров организации.

Видный венгерский экономист Я.Корнаи, изучая особенности социалистической модели экономики, сделал вывод о постоянстве существования некого разрыва между потенциальной и фактической эффективностью в функционирующих экономических системах, свидетельствующего о наличии факторов, тормозящих экономический рост. К ним он отнес неоптимальное распределение ресурсов, несовершенство методов мотивации персонала, недостаточное качество выполнения принимаемых решений, завышенные горизонты реализации капиталовложений и пр., выявление и устранение которых - существенные рычаги повышения эффективности как на уровне экономик отдельных организаций, так и стран [14]. Рассматривая основные механизмы регулирования социально-экономических процессов, он выделил административный, экономический, этический, агрессивный, самоуправляемый и семейный механизмы. При этом два первых, по его мнению, являются наиболее значимыми при регулировании эффективности.

Дополнением к взглядам П.Ф.Друкера и М.Портера на природу эффективности бизнеса является проведенная К. Хитером её дифференциация на два вида: производственную и аллокационную [15].

Производственная эффективность отражает 
способность организации производить продукцию с наименьшими издержками и состоит из двух составляющих: технической и экономической эффективности затрат. Технически эффективные организации выпускают определенный объем продукции с использованием минимально возможного объема ресурсов. В то же время, по мнению К.Хинтера, существует несколько видов технической эффективности: часть компаний реализует капиталозатратный метод производства, другие, напротив, более трудозатратный. При этом и те, и другие могут быть эффективны в зависимости от соотношения цены капитала и труда. Эффективность затрат достигается, когда фирма выбирает такой технически эффективный продукт, производство которого сводится к минимальным издержкам. Производственная эффективность, таким образом, является сочетанием технической и затратной эффективности, а вероятная затратная эффективность предопределяется структурой отрасли, связанной с монопольной властью фирмы.

Если имеет место монопольное положение организации, то затратная неэффективность может быть недостаточным аргументом в пользу изменений технической эффективности из-за слабого конкурентного давления на компанию со стороны других экономических субъектов. Для управления эффективностью менеджменту необходима информация как об уровне и структуре собственных затрат, так и об их состоянии в компаниях-конкурентах, а также потенциальных угрозах внутренней и внешней экономической среды. Однако производственная эффективность не учитывает в полной мере состояние и приоритеты общественных интересов.

Аллокационная эффективность (эффективность с позиции распределения ресурсов), напротив, отражает результат распределения общественных ресурсов с точки зрения клиентских предпочтений. Оптимальный уровень производства достигается в точке, где предельные издержки равны предельной ценности товаров, представленной кривой спроса. В условиях действия совершенной конкурентной системы прибыль становится главным элементов в достижении эффективного распределения ресурсов. Если в отрасли формируется нормальная прибыль на вложенный капитал, в результате повышения спроса для достижения рыночного равновесия повышается цена и, как результат, обеспечивается более высокая норма прибыли.
Однако она носит краткосрочный характер, так как привлечение в отрасль дополнительных ресурсов восстанавливает долгосрочное рыночное равновесие, при котором компании аллокационно эффективны и выпускают продукцию в условиях равенства предельных издержек и предельного спроса.

В условиях развития дисфункций действующих экономических институтов актуальным становится мера адаптивности системы. Под адаптивностью понимается способность организации приспосабливаться к меняющимся условиям состояния среды без угрозы качественного и количественного ухудшения основных показателей, характеризующих уровень конверсии финансового, материального и человеческого капитала в материальные и нематериальные ценности. В связи с этим появляется феномен адаптивной эффективности, которая, в отличие от аллокационной, представляет эффективность действующих правил поведения системы, задающих ей позитивную временную динамику развития.

Адаптивная эффективность характеризует способность экономической системы к обучению, стимулированию и управлению инновационным процессом, поиску более совершенных и своевременных смен форм организации производственных и управленческих процессов, управлению рисками развития и выбору оптимальной его траектории. Адаптивная эффективность тесно связана с аллокационной. Рост адаптивной эффективности возможен лишь при условии достижения определенного уровня аллокационной эффективности. В то же время её уровень предопределяется способностью организации приспосабливаться к меняющимся условиям хозяйственной деятельности.

В «Кратком курсе МВА», подготовленном преподавателями дарденской школы бизнеса, подчеркивалось, что при оценке эффективности по величине добавленной стоимости или прибыльности, важно помнить о трудностях реализации за один период как всех производственных затрат, так и результатов. Накопленные результаты могут проявляться в будущем. Если сокращение расходов достигается за счет качества и будущей репутации, то рост прибыли в краткосрочной перспективе создаст ложную картину, поэтому корректнее пользоваться показателями долговременной прибыльности [16].

Традиционные показатели эффективности 
бизнеса - прибыль и стоимость бизнеса, соответствующие интересам ключевых собственников бизнеса, могут являться контрпродуктивными с позиций продолжающейся деятельности, так как их формирование может происходить в ущерб интересам остальных групп стейкхолдеров. Очевидно, устойчивое развитие и максимальная результативность бизнеса может быть обеспечена лишь при достижении устойчивого консенсуса интересов всех участников бизнесдеятельности [17].

В своих ранних научных работах американский экономист Дж.Стиглиц подчеркивал, что центральной проблемой современных экономик является задача обеспечения совместимости интересов групп заинтересованных лиц [18]. Анализируя причины негативных результатов реформирования национального хозяйства в России, он отмечал, что положенная в основу приватизации акционерная теория, основанная на принципах приоритетности меркантильных интересов акционеров, технике агентского управления и мониторинге роста чистых активов, являлась неадекватной фактическим целям и задачам компании. Агентская модель представляет собой оценку организации как субъекта, находящегося в отношениях со многими группами заинтересованных лиц, а не только акционерами, включая институты власти, что, по его мнению, соответствует лучшей форме организации ведения бизнеса. Отмечая несовершенство акционерной теории фирмы, Стиглиц подчеркивал, что, оставаясь за пределами нового распределения собственности, заинтересованные лица реагировали на это недружественными способами, когда для того, чтобы провести реструктуризацию в новых условиях требовалось их полное сотрудничество.

Теория заинтересованных групп, развитая в научных исследованиях В.Л.Иноземцева, предполагает необходимость реализации механизма диффузии отношений собственности по отношению к широкому кругу заинтересованных лиц, реализующих принцип социальной ответственности бизнеса перед обществом [19].

Вопросы современного механизма управления собственностью вне компании исследовались в работах проф. Г.Клейнера, который, основываясь на принципах системной парадигмы Корнаи, подчеркивал особую важность для эффективной организации деятельности информационно-когнитивных аспектов вза- имодействия среды и предприятия, телеологического подхода к анализу экономического субъекта [20]. Информационно-аналитическое обеспечение системы управления заинтересованных групп предполагает учет её особенностей:

- делегирования части прав не собственникам (работникам, государственным институтам) и ограничение прав титульных собственников законом или коллективным договором вплоть до права только на получение дохода как оплаты за авансированный ими капитал;

- привлечение работников к участию распределения доходов своей компании;

- личная заинтересованность работников в результатах деятельности организации и, как следствие, усиление их творческой активности и вовлеченности в бизнес [21].

Такой подход основывается на использовании теории содержания мотивации, базирующейся на выстраивании социальных отношений, разработанной А.Маслоу [22], и предполагает использование модели социотехнической системы проектирования работы, разработанной О. С. Виханским и А. И. Наумовым [23].

В пределах предпринимательской модели ведения производства ресурсы привлекаются и используются на уровне экономического субъекта в определенной степени автономно с определенной степенью риска, поэтому отдельно рассматривается так называемая организационная эффективность, имеющая принципиальное значение при любом способе ведения производства. Все мероприятия организационного характера должны преследовать цель достижения поставленных перед организационно обособленным объектом управления задач, которые каскадируют цели более высокого уровня на конкретном уровне управления: стратегическая бизнес-единица, бизнес-процесс, хозяйственная операция, рабочее место. Оценка степени влияния тех или иных организационных мер на уровень достижения поставленных перед объектом целей представляет сложную задачу, решение которой позволяет реализовать функцию планирования развития бизнеса, обеспечив позитивный результат воздействия саморегулирования и самоорганизации на уровне объекта управления. Её решение возможно на основе формулирования основных критериев организационной эффективности - характеристики способностей объекта управления к самоорга- 
низации и саморегулированию. Для оценки эффективности организационных мероприятий выделяют эффективность адаптации, эффективность координации, эффективность мотивации [26].

Эффективность адаптации. Процесс адаптации может происходить разными способами: организационная структура обладает высокой гибкостью, что обеспечивает адекватные изменения функций без изменения организационной формы, либо изменения функционального наполнения невозможно без изменения организационной формы. Время адаптации - важнейшая оценка эффективности: от скорости коррекции целей и поведения зависят перспективы дальнейшего развития и риски наступления нежелательных последствий в результате запаздывающего реагирования на внешние возмущения. Затраты на адаптацию сопряжены с издержками, которые понесет компания при осуществлении системы мероприятий, связанных с реализацией организационных изменений на различных уровнях: замена оборудования и переквалификация работников, ликвидация, перепрофилирование или организацию новых подразделений или рабочих мест в рамках действующих и пр.

Эффективность адаптации предопределяется следующими факторами:

- определенностью алгоритма принятия решений с делегированием части полно- и правомочий в этой области на нижние уровни иерархии, что достигается наилучшим образом в клиентско-ориентированных горизонтальных структурах;

- гибкостью использования ресурсов, что обеспечивается технологическими и личностными, в том числе квалификационными характеристиками персонала;

- избыточностью производственных мощностей и иного ресурсного обеспечения, гибким режимом их использования.

Эффективность координации. Сложные иерархические бизнес-структуры, обеспечивающие наивысшие уровни часовой производительности занятого на рабочем месте работника, нуждаются в значительных усилиях для обеспечения координации действий рабочих мест. При выборе компромисса между автономией, связанной с делегированием полномочий принятия решений на уровни организационных единиц и, тем самым, сокращением издержек на планирование и контроль, и ростом затрат на согласование, принимаемых независимыми центрами управления решениями целесообразно руководствоваться критериями:

- рыночной эффективности, характеризующей уровень согласованности поведения организации на рынках сбыта и закупок, и определяемой ростом координации действий в части обслуживания клиентов, достижением эффекта синергии территориальной и продуктовой сегментации, усилением позиций компании по отношению к поставщикам за счет эффекта масштаба;

- эффективности процесса, определяемой качеством временно-логической последовательности его рабочих действий. Количественно критерий оценивается с помощью таких процессных показателей как затраты по процессу, время выполнения и качество процесса. Важным признаком эффективности процесса является количество и качество организационных интерфейсов. Использование затрудненных к пониманию интерфейсов приводит к повторным работам и, следовательно, к увеличению затрат по процессу, к проблемам согласования действий, повышающих вероятность ошибок и, как следствие, оказывает негативное влияние на качество технопроцесса;

- эффективности ресурсов, характеризующей рациональность и результативность их использования. Эффективность использования ресурсов, как правило, снижается в том случае, если различными структурными подразделениями автономно планируется одновременное использование ресурса, который находится в минимуме;

- эффективность делегирования проявляется, если задачи локальной оптимизации не противоречит достижению общих целей. На верхнем уровне должны приниматься исключительно те решения, которые невозможно эффективно делегировать на нижние уровни иерархии.

Эффективность мотивации. Делегирование правомочий на уровень рабочих мест и руководителей процессов будет иметь положительный эффект лишь в том случае, если их действия будут согласованы с целями компании. В этой связи объективно возрастает важность разработки и применения системы поощрений персонала, приводящей к:

- укреплению чувства личной ответственности у работников; 
- созданию целостных комплексов задач. Сокращение производственных связей между разными организационными единицами способствует прозрачности поставленных перед сотрудниками задач, что позволяет точнее идентифицировать и сопоставлять затраты и результаты.

Рассматривая диалектику взглядов на эффективность бизнеса необходимо подчеркнуть, что если в узком смысле эффективность традиционно рассматривалась как процессная экономичность и продуктивность, то в настоящее время в её орбиту включаются вопросы экономического роста и долгосрочной результативности. Ликвидация противоречия между текущей экономичностью и долгосрочной результативностью предполагает создание механизма достижения рациональной координируемости развития компании во времени и пространстве. Любая организация при осуществлении текущей, инвестиционной и финансовой деятельности вступает в хозяйственные связи с многочисленными рыночными агентами, совершая многочисленные трансакции. Результатом каждой хозяйственной операции становится формирование добавленной стоимости. Причем плотность процесса создания добавленной стоимости нарастает по мере участия организации в различных цепочках, складывающихся в решетки стоимости. Увеличение числа цепочек, в которых участвует компания, при условии их эффективной координации, обеспечивает хеджирование рисков и повышение плотности потоков создания стоимости для различных групп стейкхолдеров бизнеса [24]. Рациональное позиционирование, основанное на предвидении, идентификации целей и критических факторов успеха их достижения в сценарном анализе дает возможность осуществлять упреждающее реагирование на ожидаемые изменения состояния среды и учитывать корректировку приоритетов стейкхолдеров. Многообразие интересов предполагает применение системы индикаторов состояния и динамики внутренней (функциональной и процессной) и внешней (процессной) экономической среды для прогнозирования развития и мониторинга состояния бизнеса. При этом в сферу интересов анализа включены технологические, технические, экологические и социальные аспекты состояния, предусматривающие использование многокритериальных систем аналитической оценки эффективности бизнеса.

\section{Библиографический список}

1. Риккардо Д. Избранные работы по экономике. / пер. с англ.-М.: Эксмо. 2010.

2. Маркс К., Энгельс Ф. Капитал. / Сочинения: 2-е изд.- М.: Государственное издательство политической литературы. 1955-1981. т.1.

3. Шумпетер Й.А. Теория экономического развития. Капитализм, социализм и демократия / пер. с нем. - М.: Эксмо. 2008. 864 с.

4. Кейнс Д. М. Общая теория занятости, процента и денег. / Соч., пер. с англ.- М.: Гелиос АРВ, 2002.352 с.

5. Сорокин Г.М., Ванер Й., Швантнерова И. и др. Экономическая эффективность при социализме: проблемы теории и практики. / М.: Наука. 1979. 335 с.

6. Канторович Л. В. Математические методы организации и планирования производства. / Изд.: ЛГУ. 1939.67 c.

7. Немчинов В. С. Экономико-математические методы и модели./ М.: Издательство социально-экономической литературы. 1962.410 с.

8. Новожилов В.В. Проблемы измерения затрат и результатов при оптимальном планировании. / М.: Наука. 1972. 434 c.

9. Федоренко Н.П. О разработке системы оптимального функционирования экономики. / М.: Наука, 1968. 243 c.

10. Алле М. Условия эффективности в экономике. / М.: Научно-издательский центр «Наука для общества». 1998. $302 \mathrm{c.}$

11. Друкер П. Эффективное управление. Экономические задачи и оптимальные решения / пер. с англ.- М: ФАИР-ПРЕСС. 2001. 288 с.

12. Деминг Эдв. Выход из кризиса: новая парадигма управления людьми, системами и процессами: перевод с английского / 2-е изд.- М.: Альпина Бизнес Букс. 2009. 418 с.

13. Портер М. Конкуренция. / пер. с англ.-М.: Вильямс. 2005. 602 с. 
14. Корнаи Я. Социалистическая система: Полит. экономия коммунизма. / пер. с англ.- М.: Журн. Вопр. Экономики. 2000. $671 \mathrm{c.}$

15. Хитер К. Экономика отраслей и фирм: учеб пособие. / пер. с англ.- М.: Финансы и статистика. 2004. 477 с.

16. Брунер Р.Ф., Икер М.Р., Фримен Р.Э., Спекман Р.Е., ТайсбергЭ.О. Краткий курс МВА / пер. с англ.- М.: Олимп-Бизнес. 2005. 364 с.

17. Ришар Ж. Аудит и анализ хозяйственной деятельности предприятия / пер. с фр.- М.: Аудит. 1997. 375 с.

18. Стиглиц Дж. Quis qustodiet ipsos qusttodes. Неудачи корпоративного управления при переходе к рынку // Экономическая наука современной России.2002. № 4. С. 108-146.

19. Иноземцев В.Л. Концепция постэкономического общества: теоретические и практические аспекты: дис. док. экон. наук: 08.00.01. / М.: Институт МЭ и МО РАН. 1998. 392 с.

20. Клейнер Г. Системная парадигма и теория предприятия // Вопросы экономики. 2002. № 10. С. 47-69.

21. Булыга Р., Кохно П. Экономическая стратегия России на основе теории прибавочной стоимости. Новый подход, базирующийся на концепции интеллектуального капитала // Интеллектуальная собственность. Промышленная собственность. 2008. № 1. С. 30-42.

22. Маслоу А. Маслоу о менеджменте: Самоактуализация. Просвещ. менеджмент. Орг. Теория. / Питер: ГИПК Лениздат. 2003. 413 с.

23. Виханский О.С., Наумов А. И. Менеджмент: учебник. / 4-е изд., перераб. и доп.- М.: Экономистъ. 2006. 669 с.

24. Бердников В.В., Гавель О.Ю. Перспективы применения стратегического анализа данных в условиях реализации модели адаптивного управления бизнесом. // Аудит и финансовый анализ. 2014. № 6. С. 239-252.

25. Mintzberg H. The Rise and Fall of Strategic Planning // Harvard Business Review. January 31. 1994.

26. Frese E. Grundlagen der Organization: Entscheidungsorientiertes Konzept der Organisationsgestaltung / Erich Frese. - 9. ueberarb. Auflage. Wiesbaden: Gabler. 2005. XXI. 721 p. 